\title{
Burnout and work stress among medical oncologists: Egyptian multi-centric study
}

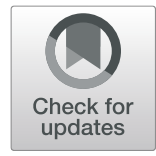

\author{
M. R. Soltan ${ }^{\text {* }}$, S. S. Soliman², S. A. Al-Hassanin ${ }^{3}$, W. A. ElSherief ${ }^{4}$, M. S. Elnaggar ${ }^{5}$ and S. F. Gohar ${ }^{3}$
}

\begin{abstract}
Background: Cancer-care health professionals are at great risk of workplace stress and high burnout levels. Only a few studies were studying the prevalence of workplace stress and burnout in medical oncologists in Egypt. The aim of the work is to study the prevalence of burnout levels and work stress among medical oncologists working at multi-centers in Egypt (Cairo, Menoufia, Fayoum, and Assiut university hospitals). A cross-sectional study was conducted on a total of 100 medical oncologists at four medical oncology centers in Egypt. Self-administered Maslach Burnout Inventory (MBI) questionnaire and Workplace Stress Scale (WSS) were used to assess the burnout and stress levels respectively among the participants.

Results: Out of 100 participants, 32\% were overall burnout positive as they met the criteria for all the burnout subscales. The percentages of emotional exhaustion, depersonalization, and reduced personal capacity were 30\%, $30 \%$, and $25 \%$, respectively. About $60 \%$ were having job stress. The present study showed that younger age $(\leq 40$ years), female gender, being single, with no children, junior physicians (residents or physicians $<10$ years in practice), with work time directed to both patient care and research, and those with more than 6 shifts per month were associated with higher burnout and workplace stress.

Conclusion: Medical oncologists experienced high burnout levels and workplace stress. More studies are needed to assess these problems in large scales to try to mitigate them.
\end{abstract}

Keywords: Work stress, Burnout, Oncologists, Egypt

\section{Background}

Burnout is a highly important issue to be taken care of in any professions dealing directly with people, including medical professions, and has its effects on nations' productivity and service quality [1].

The work stress has a direct consequence on physical and psychological aspects of oncology members. A great range of healthcare workers including physicians and nurses in cancer centers may experience high level of burnout. It is extremely stressful to work with cancer patients particularly to those diagnosed with an end-stage disease [2].

\footnotetext{
* Correspondence: Dr.mohamedsoltan1979@gmail.com

${ }^{1}$ Department of Psychiatry, Faculty of Medicine, Fayoum University, Fayoum 63514, Egypt

Full list of author information is available at the end of the article
}

Forty-five percent of the medical oncologists affiliated to the American Society of Clinical Oncology (ASCO) have high burnout levels in the subscale of emotional exhaustion and/or depersonalization [3]. Numerous studies have tried to explore the effect of work on the psychological health of oncologists [4].

The objective of this study was to identify the burnout and associated factors among medical oncologists working at multi-centers in Egypt (Cairo, Menoufia, Fayoum, and Assiut university hospitals) and to assess the level of workplace-related stress among them.

\section{Methods \\ Study population}

This cross-sectional study was conducted on volunteering oncologists working at four medical oncology centers, of four clinical oncology departments in four 
Faculties of Medicine in Egypt after approval by the Research Ethics Committee of Menoufia University.

This study was carried out at Cairo university hospitals (large center in the capital of Egypt), Menoufia university hospital (large center in Delta), and Fayoum and Assiut university hospitals (large centers in Upper Egypt), between January and June 2019. A total of 100 oncologists at these centers volunteered to participate. Informed written consent to participate and publish was obtained from each participant. The confidentiality of participants was preserved.

Each participant filled out a self-administrated questionnaire consisting of three parts. Sociodemographic and occupational background were administered in the first part. The second part presented the validated Arabic version of the Maslach Burnout Inventory (MBI) which was administered to assess burnout [5]. It included 22-items containing three subscales: the emotional exhaustion (EE) (9 items), the depersonalization (DP) (5 items), and the personal accomplishment (PA) (8 items). Burnout was defined as high scores of EE, high scores of DP, or low scores of PA. The subscale total scores were 54 for emotional exhaustion, 48 for personal accomplishment, and 30 for depersonalization. The level of burnout was high if emotional exhaustion was $\geq 27$, PA was $\leq 21$, and DP was $\geq 13$; moderate if EE was 17-26, personal accomplishment was $38-22$, and depersonalization was $7-12$; and low if emotional exhaustion was $\leq 16$, personal accomplishment was $\geq 39$, and depersonalization was $\leq 6$ [5].

Last in the 3rd part, participants received the Workplace Stress Scale to determine stress level [6]. Workplace Stress Scale is a Likert type scale with 8 questions and 5 responses to each question. Each response option is scored from (1-5), i.e., (1) never, (2) rarely, (3) sometimes, (4) often, and (5) very often. The interpretation of WSS scores is as follows: score of 15 or lower [no stress], score 16 to 20 [low stress], score 21-25 [moderate stress], score 26-30 [severe stress], score 31-40 [highly severe stress].

\section{Statistical analysis}

Results were analyzed by the statistical package for social science (SPSS) version 23 [7]. Chi-square test $\left(\chi^{2}\right)$ was used to study association between qualitative variables. Whenever any of the expected cells were less than five, Fisher's exact test was used. Odds ratio for potential risk factors for overall burnout or stress was reported from univariate logistic regression analysis. Two-sided $P$ value $<0.05$ was considered statistically significant.

\section{Results}

Out of our sample (100 participants), 40\% were aged $\leq$ 30 years, $60 \%$ were females, and $60 \%$ were married and $45 \%$ had at least one child (45\%). Forty percent of the studied oncologists were married to doctors, and $45 \%$ had a satisfactory income (Table 1).

About one third (35\%) of the responders were residents, $55 \%$ worked $>28 \mathrm{~h}$ per week, $70 \%$ had their work time directed mainly to both patients' care and scientific research (Table 2). Seventy-three percent of them were on duty all the week, $65 \%$ had more than 6 shifts per month (during weekdays from $8 \mathrm{PM}$ to $8 \mathrm{AM}$ or weekend shifts), and most of them reported that oncology work is boring (73\%) (Table 2).

The prevalence of burnout and work stress among oncologists is shown in Table 3. Out of 100 subjects, 32\% were overall burnout positive (95\% CI $23.67-41.66 \%$ ) in all burnout subscales, while the percentages of those who were suffering EE, DP, and reduced PA were $30 \%$, $30 \%$, and $25 \%$, respectively. About two-thirds of the responders (60\%, 95\% CI 49.7-69.52\%) had workplace stress as defined by the Workplace Stress Scale created by the American Institute of Stress (AIS).

Overall burnout and job stress were significantly higher among oncologists who were females, $\leq 40$ years of age, had a satisfactory income, single or divorced, and had no children (Table 4). Oncologists who have less

Table 1 Sociodemographic characteristics of the studied oncologists

\begin{tabular}{ll}
\hline Personal characteristics & $\boldsymbol{N}=100(\%)$ \\
\hline Age (years) & $40(40.0)$ \\
$20-29$ & $20(20.0)$ \\
$30-39$ & $20(20.0)$ \\
$40-49$ & $15(15.0)$ \\
$50-59$ & $5(5.0)$ \\
$>60$ & \\
Gender & $40(40.0)$ \\
Male & $60(60.0)$ \\
Female & \\
Relationship status & $30(30.0)$ \\
Single & $60(60.0)$ \\
Married & $10(10.0)$ \\
Divorced & $35(35.0)$ \\
No children & $45(45.0)$ \\
At least one child & $20(20.0)$ \\
$\geq 2$ children & \\
Partner or spouse's current profession? $(\boldsymbol{n}=\mathbf{6 0})$ \\
Physician \\
Others \\
Income & $40(66.7)$ \\
Able to save & $20(33.4)$ \\
Satisfactory & \\
Not satisfactory & $25(25.0)$ \\
\hline & $45(45.0)$ \\
& $30(30.0)$ \\
\hline
\end{tabular}


Table 2 Professional characteristics and working conditions of the studied oncologists

\begin{tabular}{ll}
\hline Professional characteristics & $\boldsymbol{N}=100(\%)$ \\
\hline Years in practice & $50(50 \%)$ \\
$<10$ & $30(30.0)$ \\
$10-19$ & $20(20.0)$ \\
$\geq 20$ & \\
Academic status & $13(13.0)$ \\
Professor & $12(12.0)$ \\
Assistant professor & $20(20.0)$ \\
Lecturer & $30(30.0)$ \\
Assistant lecturer & $35(35.0)$ \\
Resident & \\
Hours worked per week & $45(45.0)$ \\
$\leq 28$ & $55(55.0)$ \\
$\geq 28$ & \\
Work time directed mainly to & $30(30.0)$ \\
Patient care only & $0(0.0)$ \\
Research only & $70(70.0)$ \\
Both & $73(73.0)$ \\
On duty all week & $27(27.0)$ \\
Yes & \\
No & $73(73.0)$ \\
No & $27(27.0)$ \\
Yes & \\
Yncology work is boring & $35(35.0)$ \\
No & $65(65.0)$ \\
\hline & \\
\hline & \\
\hline & \\
\hline
\end{tabular}

than 10 years in practice and those who work more than 6 shifts per month showed significantly higher rates of work stress $(P<0.05)$ (Table 5$)$.

\section{Discussion}

Oncologists are liable to burnout syndrome due to the task of caring for cancer patients and their families, in addition to the psychological stressors related to their suffering $[8,9]$.

In this study, the overall prevalence of those experiencing burnout among oncologists was $32 \%$. High burnout rates for the emotional exhaustion, depersonalization, and personal accomplishment subscales were found to be $30 \%, 30 \%$, and $25 \%$, respectively. This was consistent with the global frequency of burnout over the past decade for the medical oncologists in the USA, Australia, and Europe [2, 10-12]. In 2005, the study by Allegra et al. [9] of over 1700 medical oncologists found that nearly $62 \%$ of medical oncologists in the USA
Table 3 Distribution of burnout and workplace stress scale grades among oncologists

\begin{tabular}{ll}
\hline & Overall $(\boldsymbol{n}=100)$ \\
\hline Maslach Burnout Inventory Scores & \\
Emotional exhaustion & $35(35 \%)$ \\
Low & $35(35 \%)$ \\
Moderate & $30(30 \%)$ \\
High (burnout) & \\
Depersonalization & $34(34 \%)$ \\
Low & $36(36 \%)$ \\
$\quad$ Moderate & $30(30 \%)$ \\
High (burnout) & \\
Personal accomplishment & $45(45 \%)$ \\
High & $30(30 \%)$ \\
$\quad$ Moderate & $25(25 \%)$ \\
$\quad$ Low (poor score) & $32(32 \%)(\mathbf{9 5} \% \mathrm{Cl} \mathbf{2 3 . 6 7 - 4 1 . 6 6 \% )}$ \\
Overall burnout positive & \\
Work Place Stress Scale Grades & \\
Fairly low & $\mathbf{4 0}(\mathbf{4 0 . 0 \% )}$ \\
Moderate & $25(25.0 \%)$ \\
Severe & $25(25.0 \%)$ \\
Dangerous & $10(10.0 \%)$ \\
Overall workplace stress positive & $\mathbf{6 0}(\mathbf{6 0} \%) \mathbf{9 5 \%} \mathbf{C l} \mathbf{4 9 . 7 - 6 9 . 5 2 \%}$ \\
\hline
\end{tabular}

experienced specific symptoms of burnout, including three signs: frustration (78\%), emotional exhaustion (69\%), and lack of work satisfaction (50\%). Also, $45 \%$ of the American Society of Clinical Oncology (ASCO) members have described experiencing EE and/or DP symptoms of burnout [2]. In Australia and Europe, burnout rates vary significantly, from 52 to $78 \%$ based on the tools used in screening, specialty of medical oncology, health care systems, and practice [10-12]. For example, in Australia, 57\% wished to reduce work hours, $43 \%$ reported a desire to leave their current position, $36 \%$ of gynecologic oncologists showed a high degree of EE, and 29\% considered retirement [12]. In France, a study of 340 medical and radiation oncologists using the Maslach Burnout Inventory (MBI) found that $44 \%$ believed burnout was prevalent, with a desire to stop working in medicine [11].

The same results were found in members of oncology center in a survey study in Turkey where $42 \%$ had high scores of emotional exhaustion, 20\% had high scores of depersonalizations, and $35.6 \%$ had low scores of personal accomplishment [13]. Also, this was consistent with Elen et al. [14] who reported job stress and a high level of burnout in medical oncologists.

In this study, more than half of the included oncologists suffered from stress. This finding supported the 
Table 4 Relation of burnout subscales and workplace stress to the sociodemographic data of the studied oncologists

\begin{tabular}{|c|c|c|c|c|}
\hline Sociodemographic characteristics & Overall burnout ** positive $\boldsymbol{n}=32 \boldsymbol{n}(\%)$ & Odds ratio & Workplace stress $\boldsymbol{n}=60 \boldsymbol{n}(\%)$ & Odds ratio \\
\hline \multicolumn{5}{|l|}{ Age } \\
\hline$\leq 40$ years $(60)$ & $27(84.4)$ & $5.73(1.97,16.63$ & $45(75.0)$ & $5.00(2.10,11.90$ \\
\hline$>40$ years $(40)$ & $5(15.6)$ & & $15(25.0)$ & \\
\hline$P$ value & $0.001^{*}$ & & $<0.001^{*}$ & \\
\hline \multicolumn{5}{|l|}{ Gender } \\
\hline Male (40) & $8(25.0)$ & & $20(33.3)$ & \\
\hline Female (60) & $24(75.0)$ & $2.67(1.05,6.77)$ & $40(66.7)$ & $2.00(0.88,4.54)$ \\
\hline$P$ value & $0.035^{*}$ & & 0.095 & \\
\hline \multicolumn{5}{|l|}{ Marital status } \\
\hline Single and divorced (40) & $25(78.1)$ & $12.62(4.57,34.83)$ & $35(58.3)$ & $9.80(3.37,2.90)$ \\
\hline Married (60) & $7(21.9)$ & & $25(41.7)$ & \\
\hline$P$ value & $<0.001^{*}$ & & $<0.001^{*}$ & \\
\hline \multicolumn{5}{|l|}{ Number of children } \\
\hline 0 children (35) & $24(75.0)$ & $15.55(5.56,43.46)$ & $32(53.3)$ & $14.10(3.91,50.76)$ \\
\hline $1 \geq$ child $(65)$ & $8(25.0)$ & & $28(46.7)$ & \\
\hline$P$ value & $<0.001^{*}$ & & $<0.001^{*}$ & \\
\hline \multicolumn{5}{|l|}{ Income } \\
\hline Satisfactory (70) & $25(78.1)$ & $1.83(0.69,4.85)$ & $45(75.0)$ & $1.80(0.76,4.28)$ \\
\hline Not satisfactory (30) & $7(21.9)$ & & $15(25.0)$ & \\
\hline$P$ value & 0.22 & & 0.18 & \\
\hline
\end{tabular}

${ }^{*}$ Significant at $P \leq 0.05$ level

** Burnout defined as high emotional exhaustion or depersonalization or low professional accomplishment

concern that oncologists working in clinical oncology departments are experiencing high levels of distress which was the same for the majority of oncologist worldwide $[15,16]$.

Many specific individual risk factors are associated with burnout and workplace stress. The present study showed that factors like younger age ( $\leq 40$ years), female gender, being single, with no children, junior physicians (residents or physicians $<10$ years in practice), with work time directed to both patients' care and research, and those with more than 6 shifts per month were associated with high burnout and workplace stress.

This was consistent with a previous study which showed that risk factors associated with high burnout levels included younger age ( $\leq 55$ years), female gender, junior oncologists (physicians $\leq 5$ years from training or residents), and single oncologists [3].

Age was considered as a causal factor for burnout and job stress as the early years of the career may be the most difficult ones. In this study, younger oncologists showed higher levels of burnout and workplace stress. Several studies have also reported that younger physicians had experienced higher levels of burnout $[10,13,17]$.

Additionally, oncologists with less than 10 years of practice and who are assigned more than 6 shifts per month showed significantly higher rates of workplace stress. These results could be explained by the fact that postgraduate study usually requires much physical and mental efforts. In Egypt, a postgraduate study needs about 3 years of study and research to get a master's degree and another 5 years for a $\mathrm{PhD}$ degree. These heavy academic needs, in addition to the stressful job as an oncologist, explain the finding that young oncologists $(<$ 10 years of practice) were the most vulnerable group to burnout and stress. Also, residents felt they do not have control over their decisions, which may cause a low score on a sense of PA and causes feelings of inadequacy. This may result in an increase in the workplace stress scale in juniors as well.

In this study, professors were less complaining of work stress, since they adapt to coping with stressors and burnout. They manage stressors better as they get older and have achieved good academic positions.

Having children and being married were found to be self-protective against all stages of burnout among cancer-care health professionals [10, 17-21]. Similarly in our study, the overall burnout positive oncologists was significantly higher in association with single marital status $(p<0.001)$ and also having children tends to be protective and statistically significant $(p<0.001)$ effect against burnout. Other studies suggested that the burnout is not related to marital status [22]. 
Table 5 Relation of burnout subscales and workplace stress to working conditions of the studied oncologists

\begin{tabular}{|c|c|c|c|c|}
\hline & Overall burnout ** positive $\boldsymbol{n}=32 \boldsymbol{n}(\%)$ & Odds ratio & Workplace stress $\boldsymbol{n}=60 \boldsymbol{n}(\%)$ & Odds ratio \\
\hline \multicolumn{5}{|l|}{ Years in practice } \\
\hline$<10$ years $(50)$ & $20(62.5)$ & $2.11(0.89,4.99$ & $40(66.7)$ & $6.00(2.45,14.68)$ \\
\hline$\geq 10$ years $(50)$ & $12(37.5)$ & & $20(33.3)$ & \\
\hline$P$ value & 0.086 & & $<0.001^{*}$ & \\
\hline \multicolumn{5}{|l|}{ Work time is directed mainly to } \\
\hline Patient care only (30) & $10(31.2)$ & & $14(23.3)$ & \\
\hline Both patient care and research (70) & $22(68.8)$ & $1.09(0.44,2.71)$ & $46(76.7)$ & $2.19(0.92,5.23)$ \\
\hline$P$ value & 0.851 & & 0.074 & \\
\hline \multicolumn{5}{|l|}{ On duty all week } \\
\hline Yes (73) & $23(71.9)$ & $0.92(0.36,2.36)$ & $40(66.7)$ & $0.42(0.16,1.13$ \\
\hline No (27) & $9(28.1)$ & & $20(33.3)$ & \\
\hline$P$ value & 0.946 & & 0.129 & \\
\hline \multicolumn{5}{|l|}{$>6$ shifts per month } \\
\hline Yes (65) & $22(68.8)$ & $1.28(0.52,3.13)$ & $49(81.7)$ & $6.68(2.69,3.99)$ \\
\hline No (35) & $10(31.2)$ & & $11(18.3)$ & \\
\hline$P$ value & 0.589 & & $<0.001^{*}$ & \\
\hline \multicolumn{5}{|l|}{ Oncology work is tedious and boring } \\
\hline Yes (73) & $22(68.8)$ & $0.73(0.29,1.85)$ & $40(66.7)$ & $0.42(0.16,1.13)$ \\
\hline No (27) & $10(31.2)$ & & $20(33.3)$ & \\
\hline$P$ value & 0.511 & & 0.080 & \\
\hline
\end{tabular}

${ }^{*}$ Significant at $P \leq 0.05$ level

** Burnout defined as high EE or DP or low PA

Studies assessing the impact of gender on burnout syndrome revealed debatable results. While numerous studies did not show gender as a significant factor for burnout, others found that females demonstrated higher burnout scores than males [10,22].

In this study, the female oncologist had higher rates of burnout and workplace stress than the males. The suggested explanation for this is that most of the sample were female $(60 \%)$ and that bringing up children is exhausting for female in Egypt and therefore affecting their development of depersonalization. This was not consistent with a Turkish study which showed that female oncologists have a higher personal accomplishment and lower depersonalization levels than males [23].

In this study, oncologists who work more than 6 different shifts per month had high statistically significant stress than others. This can be explained on the basis that oncologists who were overloaded by mental and physical loads were more stressed and had higher burnout levels.

These results were consistent with other studies. For example, a Turkish study conducted on medical oncologists revealed that those who had more shifts appeared to have higher risk for burnout [21]. In another study, the highest burnout scores among physicians may be related to extended working hours and work overloads [24].
In addition, $73 \%$ of oncologists in the present study reported that oncology work is boring. This can explain the higher rate of burnout in the present study in comparison to other studies.

\section{Limitations}

The present study had several limitations. Authors choose to study a group of Egyptian university oncologists so these results may not be generalized to all the world's oncologists. Another limitation of this study was the small number of participants; it was less than what was expected. Also, because we evaluated the burnout levels at only one time, we could not know the moods of participants at that time as they were answering the questionnaire. This may lead to some confounding effects on the results.

\section{Conclusion}

Burnout and workplace stress are major problems in cancer-care health professionals. They need a wellorganized strategy to improve their job stresses. Psychometric assessment tools should monitor oncologists' psychological status, burnout, and their job stress for good quality of life. 


\section{Abbreviations}

MBI: Maslach Burnout Inventory; EE: Emotional exhaustion; DP: Depersonalization; PA: Personal accomplishment

\section{Acknowledgements}

The authors thank subjects for their participation and cooperation.

\section{Authors' contributions}

SF, SA, SS, MS, and WA analyzed and interpreted the patient data regarding the clinical data and psychometric tools, and MR was a major contributor in writing the manuscript. All authors read and approved the final manuscript.

\section{Funding}

This study did not receive any fund.

\section{Availability of data and materials}

Not applicable

\section{Ethics approval and consent to participate}

This study was approved by the Ethics Committee of Faculty of Medicine, Menoufia University. Written informed consents were obtained from subjects of the study. The number of approvals is not applicable.

\section{Consent for publication}

Not applicable.

\section{Competing interests}

"The authors declare that they have no competing interests" in this section.

\section{Author details}

'Department of Psychiatry, Faculty of Medicine, Fayoum University, Fayoum 63514, Egypt. ${ }^{2}$ Department of Public Health and Community Medicine, Faculty of Medicine, Menoufia University, Shebin Elkom, Egypt. ${ }^{3}$ Department of Clinical Oncology, Faculty of Medicine, Menoufia University, Shebin Elkom, Egypt. ${ }^{4}$ Department of Clinical Oncology \& Nuclear Medicine, Cairo University, Cairo, Egypt. ${ }^{5}$ Department of Clinical Oncology, Faculty of Medicine, Assiut University, Assiut, Egypt.

Received: 17 June 2020 Accepted: 10 July 2020

Published online: 10 September 2020

\section{References}

1. Fekry M, Mohsen N, Morsy M, El Serafy D, Salah M (2020) Burnout syndrome among psychiatrists in Egyptian mental health hospital. Middle East Curr Psychiatry 27(1):1-10

2. Whippen DA, Canellos GP (1991) Burnout syndrome in the practice of oncology: results of a random survey of 1,000 oncologists. J Clin Oncol 9: 1916-1920. https://doi.org/10.1200/JCO.1991.9.10.1916

3. Hlubocky FJ, Back AL, Shanafelt TD (2016) Addressing burnout in oncology: why cancer care clinicians are at risk, what individuals can do, and how organizations can respond. Am Soc Clin Oncol Educ Book 36:271-279

4. Travado L, Grassi L, Gil F, Ventura C, Martins C, SEPOS (2005) Physician-patient communication among Southern European cancer physicians: the influence of psychosocial orientation and burnout. Psychooncology 14:661-670

5. Maslach C, Jackson S (1986) Maslach Burnout Inventory Manual, 2nd edn. Consulting Psychologists Press, Palo Alto

6. The American Institute of Stress (AIS) Handling Job Stress Questionnaire. From: http://www.stress.org Accessed: Sep 2011.

7. Grunfeld E, Whelan TJ, Zitzelsberger L, Willan AR, Montesanto B, Evans WK (2000) Cancer care workers in Ontario: prevalence of burnout, job stress and job satisfaction. Can Med Assoc J 163(2):166-169

8. Catalan J, Burgess A, Pergami A et al (1996) The psychological impact on staff of caring for people with serious diseases: the case of HIV infection and oncology. J Psychosom Res 40:425-435 [PubMed] [Google Scholar]

9. Shanafelt T, Dyrbye L (2012) Oncologist burnout: causes, consequences, and responses. J Clin Oncol 30:1235-1241 [PubMed] [Google Scholar]

10. Allegra CJ, Hall R, Yothers G (2005) Prevalence of burnout in the U.S oncology community: results of a 2003 survey. J Oncol Pract 1:140-147 Link, Google Scholar
11. Trufelli DC, Bensi CG, Garcia JB et al (2008) Burnout in cancer professionals: a systematic review and meta-analysis. Eur J Cancer Care (Engl) 17:524-531 Medline, Google Scholar

12. Blanchard $P$, Truchot $D$, Albiges-Sauvin $L$ et al (2010) Prevalence and causes of burnout amongst oncology residents: a comprehensive nationwide cross-sectional study. Eur J Cancer 46:2708-2715 Medline, Google Scholar

13. Stafford L, Judd F (2010) Mental health and occupational wellbeing of Australian gynaecologic oncologists. Gynecol Oncol 116:526-532 Medline, Google Scholar

14. Demirci S, Yildirim YK, Ozsaran Z, Uslu R, Yalman D, Aras AB (2010) Evaluation of burnout syndrome in oncology employees. Med Oncol 27(3): 968-974

15. Elen S, Bauwens S, Baillon C, Distelmans W et al (2014) The prevalence of burnout among oncology professionals: oncologists are at risk of developing burnout. Psychooncology 23

16. Whippen DA, Canellos GP (1991) Burnout syndrome in the practice of oncology: results of a random of 1,000 oncologists. J Clin Oncol 9(10):1916-1920

17. Alacacioglu A, Yavuzsen T, Dirioz M, Oztop I, Yilmaz U (2008) Burnout in nurses and physicians working at an oncology department. Psychooncology

18. Glasberg J, Horiuti L, Novais MA, Canavezzi AZ et al (2007) Prevalence of the burnout syndrome among Brazilian medical oncologists. Rev Assoc Med Bras 53(1):85-89

19. Kuerer HM, Eberlein TJ, Pollock RE, Huschka M, Baile WF et al (2007) Career satisfaction, practice patterns and burnout among surgical oncologists: report on the quality of life of members of the Society of Surgical Oncology. Ann Surg Oncol 14(11):3043-3053

20. Liakopoulou M, Panaretaki I, Papadakis V, Katsika A, Sarafidou J et al (2008) Burnout, staff support, and coping in pediatric oncology. Support Care Cancer 16(2):143-150

21. Ozyurt A, Hayran O, Sur H (2006) Predictors of burnout and job satisfaction among Turkish physicians. QJM 99(3):161-169

22. Embriaco N, Azoulay E, Barrau K et al (2007) High level of burnout in intensivists: prevalence and associated factors. Am J Respir Crit Care Med 175(7):686-692

23. Scott E. Job burnout: job factors that contribute to employee burnout. What makes some jobs more stressful? From: www.stress.about.com Accessed: Feb 2010.

24. Olkinuora M, Asp S, Juntunen J, Kauttu K, Strid L, Aarimaa M (1990) Stress symptoms, burnout and suicidal thoughts in Finnish physicians. Soc Psychiatr Epidemiol 25:81-86 [PubMed]

\section{Publisher's Note}

Springer Nature remains neutral with regard to jurisdictional claims in published maps and institutional affiliations.

\section{Submit your manuscript to a SpringerOpen ${ }^{\circ}$ journal and benefit from:}

- Convenient online submission

- Rigorous peer review

- Open access: articles freely available online

High visibility within the field

- Retaining the copyright to your article

Submit your next manuscript at $>$ springeropen.com 